\title{
Use of a health information exchange system in the emergency care of children
}

\author{
Joshua R Vest ${ }^{1 *}$, 'Jon (Sean) Jasperson ${ }^{2}$, Hongwei Zhao ${ }^{3}$, Larry D Gamm ${ }^{4}$ and Robert L Ohsfeldt ${ }^{4}$
}

\begin{abstract}
Background: Children may benefit greatly in terms of safety and care coordination from the information sharing promised by health information exchange (HIE). While information exchange capability is a required feature of the certified electronic health record, we known little regarding how this technology is used in general and for pediatric patients specifically.

Methods: Using data from an operational HIE effort in central Texas, we examined the factors associated with actual system usage. The clinical and demographic characteristics of pediatric ED encounters $(n=179,445)$ were linked to the HIE system user logs. Based on the patterns of HIE system screens accessed by users, we classified each encounter as: no system usage, basic system usage, or novel system usage. Using crossed random effects logistic regression, we modeled the factors associated with basic and novel system usage.

Results: Users accessed the system for $8.7 \%$ of encounters. Increasing patient comorbidity was associated with a $5 \%$ higher odds of basic usage and $15 \%$ higher odds for novel usage. The odds of basic system usage were lower in the face of time constraints and for patients who had not been to that location in the previous 12 months.

Conclusions: HIE systems may be a source to fulfill users' information needs about complex patients. However, time constraints may be a barrier to usage. In addition, results suggest HIE is more likely to be useful to pediatric patients visiting ED repeatedly. This study helps fill an existing gap in the study of technological applications in the care of children and improves knowledge about how HIE systems are utilized.
\end{abstract}

\section{Background}

Health information exchange (HIE), the process of electronically sharing identified, patient-level information between different organizations,[1] is a potentially transformative solution to problems of cost,[2] timeliness,[3] patient-centeredness,[4] safety,[3] and efficiency [5] that plague the healthcare system. Furthermore, children and adolescents may especially benefit from broad and easy information sharing. First, HIE has the ability to better support the care and detection of vaccine preventable conditions by incorporating immunization histories and linking to both local public health agencies and schools $[4,6,7]$. Second, minors constitute a substantial proportion of emergency department (ED) visits in the US, [8] with infants having the highest rates of ED visits [9]. The care delivered in the ED setting may benefit the most from

\footnotetext{
* Correspondence: jvest@georgiasouthern.edu

${ }^{1}$ Health Policy \& Management, Jiann-Ping Hsu College of Public Health, Georgia Southern University, 501 Forest Drive, Statesboro, GA, 30460, USA Full list of author information is available at the end of the article
}

improved information sharing $[10,11]$. Additionally, medication errors can be particularly dangerous for children; HIE improves communication and may prevent such mistakes [12,13]. Lastly, because HIE improves coordination among providers, [14] these information system can support providers in their provision of a medical home for all patients in general and children with special healthcare needs in particular.

Current federal policy dramatically advances the prospect for widespread HIE. The Health Information Technology for Economic \& Clinical Health (HITECH) Act, part of the American Recovery \& Reinvestment Act, identified information exchange capability and connectivity as a required feature of certified electronic health records (EHRs). To eligible for any EHR incentive payments, providers must now demonstrate Meaningful Use, which includes testing of HIE capabilities [15]. Despite the high level of support for HIE, we know very little about providers' motivations to use HIE systems or the effectiveness of HIE,[16-18] beyond the fact that these information

\section{Biomed Central}

(c) 2011 Vest et al; licensee BioMed Central Ltd. This is an Open Access article distributed under the terms of the Creative Commons Attribution License (http://creativecommons.org/licenses/by/2.0), which permits unrestricted use, distribution, and reproduction in any medium, provided the original work is properly cited. 
systems are predominately accessed by a minority of providers [19] and for a minority of patients [20].

This paper aims to address the knowledge gap in HIE utilization regarding treatment of children. Previous researchers have argued for examinations of information technology for children separately from adult populations due to the particular vulnerabilities and unique needs of children $[21,22]$. In this examination, we address the question, what factors indicative of an information need or value of using HIE are associated with HIE usage? Both patient and encounter characteristics can change healthcare professionals' need for additional information. Factors such as patient complexity [23] or recent utilization $[24,25]$ increase the uncertainty associated with delivering care and could prompt use of an HIE system [26]. Conversely, some encounters have little to do with the patient's previous utilization or are relatively uniformed by information created in other organizations. Likewise, the value of seeking potentially useful information may be lessened by other factors such as time constraints [27-29]. This study examines the factors associated with actual HIE usage during children's ED encounters.

\section{Methods}

The Integrated Care Collaborative (ICC) of Central Texas is a fully functional HIE facilitating effort established in 1997 encompassing Austin, Texas area safety-net providers. The ICC exists as a separate nonprofit entity with 24 member organizations including: hospital systems, clinics, and governmental agencies. The study sample includes all ED encounters among patients less than 18 years old between $1 / 1 / 2006$ and 6/30/2009 included in the ICC's master patient index/clinical data repository, ICare. I-Care is a centralized database containing electronic patient level demographic and clinical information. ICC member organizations contribute patient level electronic data to I-Care on medically indigent patients. In turn, authorized users at each location may access data from I-Care through a secured website. Authorized users vary by location, but can include physicians, nurses, and/ or administrative staff. Parents or guardians provide consent for minors to be included in the information exchange and this study only included consenting patients. We also excluded emergency encounters occurring at facilities before the hospital employed an authorized user of the I-Care system. The final dataset included 179,445 encounters from 11 emergency departments.

We derived the dependent variable representing type of usage from the I-Care system log files. Log files provide an objective and recommended $[17,30]$ measure of system usage unbiased by subject recall [31]. The I-Care interface is an EpicWeb proprietary software system where authorized users navigate through several different web pages or screens containing demographics, prior utilization history, contact information, payer history, medication orders, prior diagnoses and other information. As part of the Health Insurance Portability and Accountability Act compliance, I-Care generates electronic $\log$ files in order to document the user's activities including: patient viewed, date accessed, time accessed, and screen(s) viewed. Through the logged date and time, we could follow the sequence of screens viewed by each user for a given patient on a given date. The entire sample included 77 different patterns of screen views in the associated $\log$ file. A single pattern accounted for $82 \%$ of sessions; this pattern consisted of an end user identifying a patient on a selection screen and then viewing a single screen containing a summary of recent encounters. We classified this type of session as basic usage. All other session patterns were classified as novel usage. A novel usage session consisted of any user session that included additional screen views (such as medications, a demographic summary, or detailed encounter records) beyond the initial patient selection screen and summary of recent encounters screen accessed in a basic usage scenario. A patient encounter in an ED could result in three usage outcomes: 1) no usage, 2) basic usage, and 3) novel usage. We linked user sessions to encounters based on patient identifier, date, user's work location, and place of encounter. Because ED encounters can occur late at night, we allowed for linkages up to 3 AM the next day.

We considered three factors as indicative of uncertainty that creates an information need: comorbidity, prior utilization, and unfamiliarity with the patient. The number of unique disease categories for each encounter measured comorbidity. Disease categories were defined by the Agency for Healthcare Research \& Quality's (AHRQ) Clinical Classifications Software applied to all reported ICD-9 diagnosis codes [32]. For prior utilization, we determined the total number of ED encounters, inpatient hospitalizations, and primary care clinic visits at ICC member facilities in the 12 months prior to the encounter date. We did not include previous visits to the same ED in these counts. Following existing definitions of encounter frequency, we divided ED and primary care visits into 0 encounters, infrequent users (1 to 3), and frequent users (4 or more) [33-35]. Due to small cell counts, we could only consider hospitalization in the previous 12 months in a binary fashion. Finally, patients unfamiliar to a specific ED were marked by the absence of any encounters at that same ED in the previous 12 months. Because we excluded visits at the same facility from the measure of past ED encounters, we avoided collinearity for this measure of patient unfamiliarity.

To measure potential time constraints, we created a binary variable to classify the encounter date at that ED as busy or not busy. For each ED, we divided the total 
number of encounters on a date by the ED's previous year's average number of daily encounters for that same day of the week and month. A busier than average day existed when this ratio was greater than one.

We categorized the primary diagnosis and payer to help describe the sample. First, AHRQ's Chronic Condition Indicator and Body Systems definitions categorized the primary diagnosis as a chronic condition and assigned the primary diagnosis into 18 indicators roughly analogous to major diagnostic categories [36]. We selected factors influencing health status and all categories that occurred in less than $1 \%$ of encounters as the reference category for the analysis. We grouped the payer associated with the encounter into Medicaid, Children's Health Insurance Program (SCHIP), charity care (sliding scale, self-pay, or charity care) and multiple or no payers reported.

Hypotheses were examined using crossed random effects logistic regression models [37]. The random intercepts account for the clustering of encounters within patients and patients within EDs. The crossed effects allow for patients with encounters at different EDs. Since the reference category is substantially larger than the outcomes of interest, independent mixed effects binary logistic equations were fit instead of a multinomial logistic regression [38]. All variables are considered as fixed effects and the models were fit using Laplacian approximation [37]. Measures of effect size were expressed odds ratios (OR). The advantage of a random effect logistic regression model is its ability to model the correlated nature of the binary data arising from a multi-level structure; it is difficult to do so using the alternative approach of the generalized estimation equations. However, the interpretation of the fixed effects from the random effect logistic regression is not very transparent, since they carry a subject-specific meaning, instead of indicating a population averaged effect. In general, the population averaged effect is smaller than the subject-specific effect [39]. Hence, we need to keep this in mind when interpreting our regression models. In the special case with logit link and one random effect, Heagerty and Zeger [40] showed that the marginal parameters were reduced by a factor that depends on the variance of the random effect. Nonetheless, the significance levels of the parameter estimates from these two types of models often stay the same.

The project was approved the Institutional Review Boards of Georgia Southern University and Texas A\&M University.

\section{Results}

The system was accessed for 15,586 of 179,445 encounters $(8.7 \%)$, which was higher than other published reports $[2,20]$. Table 1 describes the study sample. Most encounters were among males, Hispanics, and paid for by Medicaid. Patients aged 1 to 5 years old accounted for more than 4 out of 10 encounters. The four most common primary diagnoses involved ill-defined conditions (23.1\%), diseases of the respiratory system (22.9\%), injuries and poisoning (15.5\%) and diseases of the central nervous system (10.7\%).

\section{Factors associated with basic usage}

Table 2 describes the factors associated with basic usage unadjusted and adjusted for confounding. After controlling for confounding factors, several factors indicative of patient complexity increased the odds of basic usage. In terms of patient comorbidity, the odds of basic usage were $5 \%$ higher $(\mathrm{OR}=1.05$; 95\%Confidence interval $(\mathrm{CI})=1.02$, 1.08) for each additional recorded diagnosis category during the encounter. Specific to recent utilization history, increasing number of primary care visits, visits to other EDs, and prior hospitalization in the previous 12 months each increased the odds of basic usage. Contrary to expectations, the odds of basic usage were lower for unfamiliar patients $(\mathrm{OR}=0.46 ; 95 \% \mathrm{CI}=0.44,0.48)$.

Time constraints also appear to be a barrier to usage. Odds of usage were $35 \%$ lower on busier than average days in the $\mathrm{ED}(\mathrm{OR}=0.65 ; 95 \% \mathrm{CI}=0.62,0.67)$. In terms of primary diagnoses, the odds of basic usage were $19 \%$ higher for diseases of the skin, $28 \%$ higher for diseases of the musculoskeletal system and 15\% higher for injuries and poisoning. In addition, encounters with a chronic condition had 10\% higher odds of basic usage. Lastly, the odds of basic usage were higher for encounters with older pediatric patients and when more than one payer existed or the payer was unknown. The use of a random effects model is supported by the statistically significant variances for both location and patient.

\section{Factors associated with novel usage}

Table 3 displays the factors associated with novel usage. After adjusting for other factors, patient comorbidity, measured as the number of diagnoses at the encounter, positively increased the odds of novel usage (OR $=1.15 ; 95 \%$ $\mathrm{CI}=1.09,1.21)$. In addition, prior utilization of primary care and hospitalization in the previous 12 months were both positively associated with novel usage. As was the case with basic usage, the odds of novel usage were lower for unfamiliar patients $(\mathrm{OR}=0.19 ; 95 \% \mathrm{CI}=0.17,0.21)$.

Controlled for other factors, a busier than average day at the ED was not with associated novel usage. Increasing age was associated with novel usage. After adjustment, the only diagnosis category associated with novel usage was injury and poisoning $(\mathrm{OR}=0.80 ; 95 \% \mathrm{CI}=0.66,0.97)$. Encounters where the payer was not Medicaid were associated with novel usage. The odds of novel usage were $40 \%$ lower for SCHIP and 17\% higher for charity care. Again, the statistically significant variances indicated the appropriateness of the random effects model. 
Table 1 Characteristics of encounters at emergency departments among children included in the Integrated Care Collaboration, 1/1/2006-6/30/2009.

\begin{tabular}{|c|c|c|c|c|}
\hline & $\begin{array}{l}\text { All } \\
\text { encounters } \\
n=179,445\end{array}$ & $\begin{array}{l}\text { Encounters without HIE } \\
\text { usage } \\
n=163,859\end{array}$ & $\begin{array}{l}\text { Encounters with basic } \\
\text { usage } \\
n=12,910\end{array}$ & $\begin{array}{l}\text { Encounters with novel } \\
\text { usage } \\
\mathrm{n}=2,676\end{array}$ \\
\hline Female, \% & 47.9 & 48.1 & 46.2 & 46.6 \\
\hline \multicolumn{5}{|l|}{ Age, \% } \\
\hline$<1$ year & 21.6 & 21.8 & 19.1 & 23.5 \\
\hline 1 to 5 years & 44.3 & 44.5 & 53.7 & 51.6 \\
\hline 6 to 11 years & 18.9 & 18.9 & 19.0 & 15.7 \\
\hline 12 to 17 years & 15.2 & 15.8 & 8.2 & 9.2 \\
\hline \multicolumn{5}{|l|}{ Race/ethnicity, \% } \\
\hline White non-Hispanic & 19.1 & 19.6 & 13.5 & 13.0 \\
\hline African American & 12.8 & 12.7 & 13.2 & 13.5 \\
\hline Hispanic & 60.5 & 60.0 & 69.8 & 69.4 \\
\hline Other/unknown & 8.0 & 3.4 & 4.0 & 7.6 \\
\hline \multicolumn{5}{|l|}{ Payer, \% } \\
\hline Medicaid & 66.9 & 66.7 & 69.8 & 69.1 \\
\hline $\mathrm{CHIP}$ & 5.3 & 5.3 & 4.5 & 2.8 \\
\hline Charity care & 24.2 & 24.5 & 20.6 & 21.9 \\
\hline Unknown/multiple recorded & 3.7 & 3.5 & 5.1 & 6.1 \\
\hline \multicolumn{5}{|l|}{ Utilization history* } \\
\hline \multicolumn{5}{|l|}{ Clinic visits, \% } \\
\hline 0 & 78.4 & 79.4 & 69.3 & 59.4 \\
\hline 1 to 3 & 12.1 & 116. & 16.5 & 20.2 \\
\hline$\geq 4$ & 9.5 & 9.0 & 14.2 & 20.4 \\
\hline \multicolumn{5}{|l|}{ Emergency department visits, \% } \\
\hline 0 & 78.2 & 78.8 & 70.3 & 78.8 \\
\hline 1 to 3 & 19.6 & 19.1 & 26.0 & 19.0 \\
\hline$\geq 4$ & 2.3 & 2.1 & 3.8 & 2.2 \\
\hline Hospitalized, \% & 14.2 & 13.9 & 17.0 & 20.4 \\
\hline \multicolumn{5}{|l|}{ Charlson index, \% } \\
\hline 0 & 81.5 & 82.1 & 76.2 & 72.5 \\
\hline 1 & 17.0 & 16.5 & 21.6 & 24.4 \\
\hline$\geq 2$ & 1.5 & 1.4 & 2.2 & 3.1 \\
\hline Chronic condition indicator, \% & 4.6 & 4.5 & 5.7 & 6.1 \\
\hline \multicolumn{5}{|l|}{ Primary diagnosis ${ }^{\dagger}, \%$} \\
\hline Infectious \& parasitic disease & 5.7 & 5.7 & 5.9 & 6.5 \\
\hline Neoplasms & 0.0 & 0.0 & 0.0 & 0.0 \\
\hline Endocrine, metabolic \& immunity & 0.5 & 0.5 & 0.6 & 0.5 \\
\hline Diseases of the blood & 0.3 & 0.3 & 0.4 & 0.4 \\
\hline Mental disorders & 0.3 & 0.3 & 0.1 & 0.3 \\
\hline Diseases of the nervous system & 10.7 & 10.6 & 11.8 & 11.0 \\
\hline Diseases of the circulatory system & 0.1 & 0.1 & 0.0 & 0.1 \\
\hline Diseases of the respiratory system & 22.9 & 22.9 & 23.8 & 23.7 \\
\hline Diseases of the digestive system & 4.4 & 4.3 & 4.4 & 5.2 \\
\hline Diseases of the genitourinary system & 2.7 & 2.7 & 2.7 & 3.1 \\
\hline Complications of pregnancy/childbirth & 0.7 & 0.8 & 0.1 & 0.5 \\
\hline Diseases of the skin & 5.2 & 5.1 & 5.7 & 4.4 \\
\hline
\end{tabular}


Table 1 Characteristics of encounters at emergency departments among children included in the Integrated Care Collaboration, 1/1/2006-6/30/2009. (Continued)

\begin{tabular}{lllll}
\hline Diseases of the musculoskeletal & 1.6 & 1.6 & 1.6 & 1.4 \\
\hline Congenital anomalies & 0.1 & 0.1 & 0.0 & 0.0 \\
\hline $\begin{array}{l}\text { Conditions originating in the perinatal } \\
\text { period }\end{array}$ & 0.4 & 0.4 & 0.1 & 0.0 \\
\hline Injury \& poisoning & 15.5 & 15.8 & 13.9 & 9.1 \\
\hline III-defined conditions & 23.1 & 23.0 & 23.2 & 27.2 \\
\hline Factors influencing health status & 5.9 & 5.9 & 5.9 & 6.8 \\
\hline Unfamiliar patient ${ }^{\ddagger} \%$ & 52.5 & 54.4 & 33.9 & 16.8 \\
\hline Busier than average day ${ }^{\S} \%$ & 59.0 & 60.2 & 44.4 & 56.5 \\
\hline
\end{tabular}

* Not seen at the same facility in the past 12 months

${ }^{\dagger}$ Agency for Healthcare Research \& Quality's body system indicator categories

₹ Not seen at the same facility in the past 12 months

${ }^{\S}$ Ratio of the total number of same day encounters divided by the previous year's average number of daily encounters by month and day of week greater than 1.0

Table 2 Association between patient, encounter, ED characteristics and basic health information exchange usage.

\begin{tabular}{|c|c|c|}
\hline & \multicolumn{2}{|c|}{ Basic usage } \\
\hline & Unadjusted & Adjusted \\
\hline & OR $(95 \% \mathrm{Cl})^{*}$ & OR $(95 \% \mathrm{Cl})$ \\
\hline Female & $0.97(0.93,1.01)$ & $0.98(0.94,1.02)$ \\
\hline \multicolumn{3}{|l|}{ Age (years) } \\
\hline 1 to 5 vs $<1$ & $1.56(1.48,1.64)$ & $1.68(1.58,1.79)$ \\
\hline 6 to 11 vs $<1$ & $1.37(1.29,1.46)$ & $1.78(1.65,1.91)$ \\
\hline 12 to 17 vs < 1 & $1.21(1.12,1.31)$ & $1.54(1.41,1.69)$ \\
\hline \multicolumn{3}{|l|}{ Race/ethnicity } \\
\hline African American vs White $^{\dagger}$ & $1.09(1.01,1.18)$ & $1.00(0.93,1.08)$ \\
\hline Hispanic vs White ${ }^{\dagger}$ & $1.03(0.97,1.10)$ & $0.98(0.93,1.04)$ \\
\hline Other/unknown vs White ${ }^{\dagger}$ & $0.69(0.61,0.77)$ & $0.72(0.64,0.81)$ \\
\hline \multicolumn{3}{|l|}{ Payer } \\
\hline SCHIP vs Medicaid & $0.79(0.72,0.86)$ & $0.93(0.85,1.03)$ \\
\hline Charity care vs Medicaid & $0.85(0.83,0.92)$ & $0.96(0.92,1.01)$ \\
\hline Unknown/multiple vs Medicaid & $1.57(1.43,1.72)$ & $1.48(1.35,1.63)$ \\
\hline \multicolumn{3}{|l|}{ No. of primary care clinic visits ${ }^{\ddagger}$} \\
\hline 1 to 3 vs 0 & $1.49(1.41,1.57)$ & $1.47(1.39,1.55)$ \\
\hline$\geq 4$ vs 0 & $1.58(1.48,1.67)$ & $1.35(1.27,1.44)$ \\
\hline \multicolumn{3}{|c|}{ No. of emergency depart visits to other facilities ${ }^{\ddagger}$} \\
\hline 1 to 3 vs 0 & $1.75(1.68,1.84)$ & $1.60(1.52,1.67)$ \\
\hline$\geq 4$ vs 0 & $2.54(2.28,2.84)$ & $2.19(1.96,2.45)$ \\
\hline Hospitalized $^{\ddagger}$ & $1.12(1.06,1.18)$ & $1.33(1.25,1.41)$ \\
\hline No. of unique diagnosis categories & $1.07(1.05,1.10)$ & $1.05(1.02,1.08)$ \\
\hline Chronic condition indicator & $1.17(1.08,1.28)$ & $1.10(1.01,1.20)$ \\
\hline \multicolumn{3}{|l|}{ Primary diagnosis } \\
\hline Infectious \& parasitic disease & $1.00(0.90,1.11)$ & $1.00(0.90,1.11)$ \\
\hline Diseases of the nervous system & $1.16(1.06,1.27)$ & $1.07(0.97,1.17)$ \\
\hline Diseases of the respiratory system & $1.06(0.98,1.27)$ & $1.01(0.93,1.10)$ \\
\hline Diseases of the digestive system & $0.95(0.85,1.06)$ & $0.99(0.88,1.11)$ \\
\hline Diseases of the genitourinary system & $1.13(0.99,1.29)$ & $1.11(0.97,1.27)$ \\
\hline Diseases of the skin & $1.21(1.09,1.35)$ & $1.19(1.07,1.52)$ \\
\hline
\end{tabular}


Table 2 Association between patient, encounter, ED characteristics and basic health information exchange usage. (Continued)

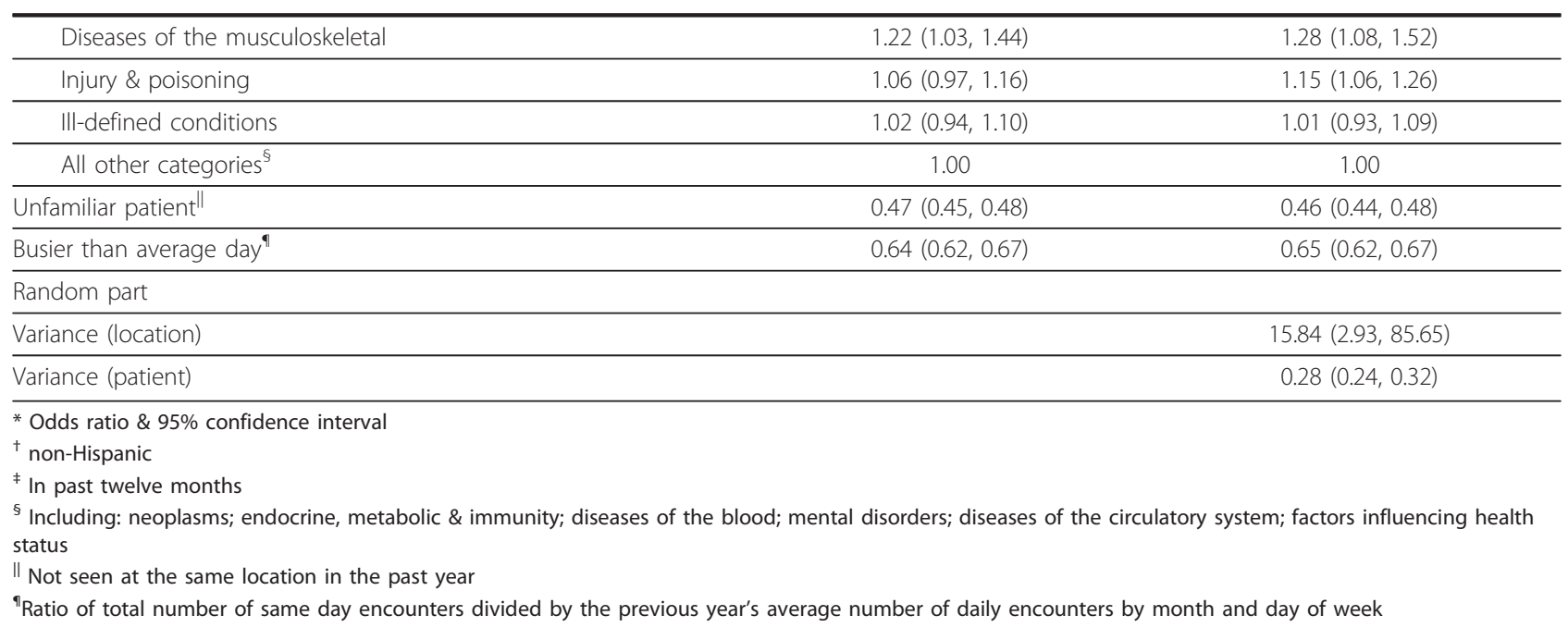

Table 3 Association between patient, encounter, ED characteristics and novel health information exchange usage.

\begin{tabular}{|c|c|c|}
\hline & \multicolumn{2}{|c|}{ Novel usage } \\
\hline & Unadjusted & Adjusted \\
\hline & OR $(95 \% \mathrm{Cl})^{*}$ & OR $(95 \% \mathrm{Cl})$ \\
\hline Female & $0.98(0.90,1.07)$ & $0.97(0.89,1.06)$ \\
\hline \multicolumn{3}{|l|}{ Age (years) } \\
\hline 1 to 5 vs $<1$ & $1.17(1.06,1.30)$ & $1.34(1.19,1.51)$ \\
\hline 6 to 11 vs $<1$ & $0.87(0.76,1.00)$ & $1.37(1.17,1.60)$ \\
\hline 12 to 17 vs $<1$ & $0.91(0.78,1.08)$ & $1.39(1.15,1.68)$ \\
\hline \multicolumn{3}{|l|}{ Race/ethnicity } \\
\hline African American vs White $^{\dagger}$ & $1.16(0.98,1.36)$ & $1.00(0.85,1.18)$ \\
\hline Hispanic vs White ${ }^{\dagger}$ & $1.09(0.98,1.10)$ & $0.82(0.72,0.93)$ \\
\hline Other/unknown vs White $^{\dagger}$ & $0.69(0.61,0.77)$ & $0.89(0.70,1.13)$ \\
\hline \multicolumn{3}{|l|}{ Payer } \\
\hline SCHIP vs Medicaid & $0.49(0.39,0.62)$ & $0.60(0.47,0.76)$ \\
\hline Charity care vs Medicaid & $0.92(0.84,1.02)$ & $1.17(1.06,1.30)$ \\
\hline Unknown/multiple vs Medicaid & $1.75(1.47,2.09)$ & $1.59(1.32,1.91)$ \\
\hline \multicolumn{3}{|l|}{ No. of primary care clinic visits ${ }^{*}$} \\
\hline 1 to 3 vs 0 & $2.20(1.97,2.45)$ & $2.19(1.96,2.45)$ \\
\hline$\geq 4$ vs 0 & $2.84(2.54,3.18)$ & $2.24(1.99,2.52)$ \\
\hline \multicolumn{3}{|c|}{ No. of emergency depart visits to other facilities ${ }^{\ddagger}$} \\
\hline 1 to 3 vs 0 & $1.11(1.00,1.24)$ & $1.04(0.93,1.16)$ \\
\hline$\geq 4$ vs 0 & $1.22(0.92,1.62)$ & $1.02(0.76,1.36)$ \\
\hline Hospitalized $^{\ddagger}$ & $1.46(1.31,1.62)$ & $1.39(1.22,1.57)$ \\
\hline No. of unique diagnosis categories & $1.22(1.67,1.29)$ & $1.15(1.09,1.21)$ \\
\hline Chronic condition indicator & $1.22(1.03,1.44)$ & $1.17(0.97,1.40)$ \\
\hline \multicolumn{3}{|l|}{ Primary diagnosis } \\
\hline Infectious \& parasitic disease & $1.00(0.81,1.23)$ & $0.98(0.79,1.22)$ \\
\hline Diseases of the nervous system & $0.97(0.81,1.17)$ & $0.88(0.72,1.06)$ \\
\hline Diseases of the respiratory system & $0.95(0.81,1.11)$ & $0.88(0.74,1.04)$ \\
\hline Diseases of the digestive system & $1.00(0.80,1.25)$ & $1.06(0.84,1.33)$ \\
\hline
\end{tabular}


summary information. This was also true in our study of adult populations [41]. In contrast, the opportunity costs incurred on a busy day did not negatively affect novel usage. This may suggest that conditions observed in the child may drive novel usage regardless of how busy the ED is, while basic usage is more easily suppressed. Information that was beyond the more in-depth or the not commonly reported, appeared worthwhile to seek out even during a busy day. In addition, charity care was associated with novel usage and encounters with unknown payers were positively associated with all types of usage. Usage during these encounters that could prove more costly to the facility may represent an attempt to locate more information about the patient or a history of payer eligibility. Finally, although previous research indicates a demand for lots of clinical data elements from HIE systems in the ED setting,[46] few diagnosis categories were associated with either type of usage.

The only primary diagnoses category associated with both types of usage was injury and poisoning, although importantly the direction of the effect differed. In general, one could assume injuries are a type of encounter where the diagnosis and treatment should not depend upon data stored in other organizations' information systems. While that view explains the negative association with novel usage it does not explain the positive relationship with basic usage. When specifically considering the case of children, other factors come into play that may explain this apparent discrepancy. Nationwide, a significant percentage of ED encounters among children are due to abuse [47]. The positive association with basic usage may be indicative of a quick check to determine if a history or pattern of injury may be discernible. This type of usage would be a great strength of HIE systems as it would detect perpetrators who utilize multiple EDs to hide repeat injuries to the same child or even vulnerable adults like the elderly or those with an intellectual disability. The positive association with novel usage is in contrast to our previous findings of HIE usage among adults ED encounters. Among adults, injuries were negatively associated with both types of usage,[41] which is logical as injuries to most adults do not carry a concern about abuse. We encourage future researchers to examine this relationship between ED injury encounters and HIE usage.

Overall, these results complement to the broader literature on the determinants of information seeking among clinicians. For example, research by Gorman and Helfand, [48] although focused on knowledge-based resources, reported information seeking was associated with the urgency of the patient's problem. A similar phenomenon was evident in this study, as an increasing number of diagnoses was associated with an increased odds of both types of system usage. Also focused on the use of knowledge- based resources, Ely and colleagues [49] identified a lack of time as a barrier; in like manner, we reported if the day had more encounters than average, the odds of routine usage decreased significantly. Lastly, investigators have begun to catalog the types of information desired by providers from HIE systems $[46,50]$. While our study does not look at system access for specific data elements, our measure of basic usage represents the factors associated with access of summary patient information.

\section{Limitations}

The results of this study are limited in more than one fashion. First, this study does not include any direct measures of the system users. For any given encounter, the system examined in this study only records use. While we can identify encounters without usage, we have no way of attributing this non-use to an individual user. In other words, while we can identify the users who employed the system, we cannot identify the users who did not use the system. Therefore, we cannot address any potential confounding due to user characteristics like job type, computer skills, or perceptions of system usability. Likewise, we did not systematically explore the potential the role of workplace characteristics. For example, computer terminals may not have been equally accessible to users in each ED or the speed of internet connection may have varied. While our random-intercept models statistically adjust for these differences, we do not explicitly model their effects. Third, our measure of usage does not include the specific data sought, search strategies, encounter workflow, or if the search was successful. Previous research demonstrates end users need a wide variety of patient information types,[51] engage in the system in very diverse ways,[52] and tighter integration into workflow improves usage rates $[20,53]$. Despite these limitations our measure of usage is more informative than previous research [54]. The logical next step in research is to examine these suggested factors qualitatively with users and the context workflow. Fourth, due to the user location and date restrictions in the linking process, we have excluded users accessing the system after a patient encounter to identify patients for disease management programs, social services, or public health. The factors associated with usage could reasonably be expected to differ among these types of users. Finally, caution is needed in generalizing this study to other types of healthcare encounters or other HIE efforts since this particular exchange only includes medically indigent patients and one particular HIE system. Other HIE systems may differ on key characteristics such as breadth of information types and sources, the display of information, or overall system usability. 


\section{Conclusions}

These findings help fill a gap in knowledge about what type of HIE use occurs for children and under what conditions. Healthcare professionals, advocates and the government believe HIE has the potential to transform healthcare and children may benefit greatly from the improved information sharing. However, the simple existence of these systems is not likely to be sufficient and assuming use will automatically follow existence is unfounded. HIE systems must be applied to the delivery of care and the improvement of patient health. The improved use of HIE to avoid duplication and improve coordination of care for pediatric patients will be increasingly important as health reform moves to extend coverage to nearly all children.

\section{Acknowledgements and funding}

This work was supported by Award Number R21CA138605 from the National Cancer Institute. The content is solely the responsibility of the authors and does not necessarily represent the official views of the National Cancer Institute or the National Institutes of Health. Also, we would like to thank Dan Brown and Anjum Khurshid at the Integrated Care Collaborative of Central Texas for their assistance with in obtaining the data for this study.

\section{Author details}

'Health Policy \& Management, Jiann-Ping Hsu College of Public Health, Georgia Southern University, 501 Forest Drive, Statesboro, GA, 30460, USA. ${ }^{2}$ Department of Information \& Operations Management, Mays Business School, Texas A\&M University, 4217 TAMU, College Station, TX, 77843, USA. ${ }^{3}$ Department of Epidemiology \& Biostatistics, School of Rural Public Health, Texas A\&M Health Science Center, 1266 TAMU, College Station, TX, 77843, USA. ${ }^{4}$ Department of Health Policy \& Management, School of Rural Public Health, Texas A\&M Health Science Center, 1266 TAMU, College Station, TX, 77843, USA.

\section{Authors' contributions}

JV conceived the research question, designed the study, analyzed the data, and drafted the manuscript. 'JJ designed the dependent variables and drafted the manuscript. $\mathrm{HZ}$ led the statistical analysis. $L G$ helped design the study and interpreted the results. RO helped design of the study, interpreted the results and draft the manuscript. All authors read and approved the final manuscript.

\section{Competing interests}

The authors declare that they have no competing interests.

Received: 21 March 2011 Accepted: 30 December 2011 Published: 30 December 2011

\section{References}

1. Report to the Office of the National Coordinator for Health Information Technology on Defining Key Health Information Technology Terms. [http://healthit.hhs.gov/portal/server.pt?open $=18 \&$ objlD $=848133 \&$ parentname $=$ CommunityPage\&parentid $=5 \&$ mode $=2 \&$ in $\_$hi_ userid $=10741 \&$ cached $=$ true].

2. Overhage J, Deter P, Perkins S, Cordell W, McGoff J, McGrath R: A randomized, controlled trial of clinical information shared from another institution. Ann Emerg Med 2002, 39:14-23.

3. Institute of Medicine: Crossing the Quality Chasm: a new health system for the 21st century Washington, D.C.: National Academy Press; 2001.

4. Department of Health \& Human Services: Information for Health: a Strategy for Building the National Health Information Infrastructure. Book Information for Health: a Strategy for Building the National Health Information Infrastructure (Editor ed.^eds.). City 2001.
5. Institute of Medicine: Fostering Rapid Advances in Health Care: Learning from System Demonstrations. Washington, D.C.: National Academy Press; 2003.

6. McDonald CJ, Overhage JM, Barnes M, Schadow G, Blevins L, Dexter PR, Mamlin B, the INPC Management Committee: The Indiana Network For Patient Care: A Working Local Health Information Infrastructure. Health Aff 2005, 24:1214-1220.

7. Hinman AR, Davidson AJ: Linking Children's Health Information Systems: Clinical Care, Public Health, Emergency Medical Systems, and Schools. Pediatrics 2009, 123:567-73.

8. Nawar E, Niska R, Xu J: National Hospital Ambulatory Medical Care Survey: 2005 Emergency Department Summary. Adv Data 2007, 1-32.

9. Pitts $S$, Niska $R, X u J$, Burt $C$ : National Hospital Ambulatory Medical Care Survey: 2006 Emergency Department Summary. National Health Statistics Reports 2008, 7:1-40.

10. Shapiro JS, Kannry J, Lipton M, Goldberg E, Conocenti P, Stuard S, Wyatt BM, Kuperman G: Approaches to patient health information exchange and their impact on emergency medicine. Annals of Emergency Medicine 2006, 48:426-432.

11. Frisse ME, Holmes RL: Estimated financial savings associated with health information exchange and ambulatory care referral. Journal of Biomedical Informatics 2007, 40:S27-S32.

12. Kaushal R, Barker KN, Bates DW: How Can Information Technology Improve Patient Safety and Reduce Medication Errors in Children's Health Care? Arch Pediatr Adolesc Med 2001, 155:1002-1007.

13. Kaelber DC, Bates DW: Health information exchange and patient safety. Journal of Biomedical Informatics 2007, 40:540-545.

14. Branger $P$, van't Hooft $A$, van der Wouden HC: Coordinating shared care using electronic data interchange. Medinfo 1995, 8(Pt 2):1669.

15. Department of Health \& Human Services: 42 CFR Parts 412, et al. Medicare and Medicaid Programs; Electronic Health Record Incentive Program; Proposed Rule. Federal Register 2010, 75:1844-2011.

16. Ash JS, Guappone KP: Qualitative evaluation of health information exchange efforts. Journal of Biomedical Informatics 2007, 40:S33-S39

17. Cusack CM, Poon EG: Health Information Exchange Toolkit. Book Health Information Exchange Toolkit (Editor ed.^eds.) City: Agency for Healthcare Research \& Quality; 2007

18. Hripcsak G, Kaushal R, Johnson KB, Ash JS, Bates DW, Block R, Frisse ME, Kern LM, Marchibroda J, Overhage JM, Wilcox AB: The United Hospital Fund meeting on evaluating health information exchange. Journal of Biomedical Informatics 2007, 40:S3-S10.

19. Grossman JM, Bodenheimer TS, McKenzie K: MARKETWATCH: HospitalPhysician Portals: The Role Of Competition In Driving Clinical Data Exchange. Health Affairs 2006, 25:1629-1636.

20. Johnson KB, Gadd C, Aronsky D, Yang K, Tang L, Estrin V, King JK, Frisse ME: The MidSouth eHealth Alliance: Use and Impact In the First Year. AMIA Annu Symp Proc 2008, 333-337.

21. Kim GR, Lehmann CU, the Council on Clinical Information Technology: Pediatric Aspects of Inpatient Health Information Technology Systems. Pediatrics 2008, 122:e1287-1296.

22. Menachemi N, Brooks RG, Schwalenstocker E, Simpson L: Use of Health Information Technology by Children's Hospitals in the United States. Pediatrics 2009, 123:S80-84.

23. van den Akker M, Buntinx F, Metsemakers JF, Roos S, Knottnerus JA: Multimorbidity in general practice: prevalence, incidence, and determinants of co-occurring chronic and recurrent diseases. J Clin Epidemiol 1998, 51:367-375.

24. Gandhi TK, Sittig DF, Franklin M, Sussman AJ, Fairchild DG, Bates DW: Communication breakdown in the outpatient referral process. J Gen Intern Med 2000, 15:626-631.

25. National Research Council: Networking Health: prescriptions for the internet Washington, D.C.: National Academy Press; 2000.

26. Vest JR: Health information exchange and healthcare utilization. Journal of Medical Systems 2009, 33:223-231.

27. Ely JW, Osheroff JA, Chambliss ML, Ebell MH, Rosenbaum ME: Answering physicians' clinical questions: obstacles and potential solutions. J Am Med Inform Assoc 2005, 12:217-224

28. McKnight LK, Stetson PD, Bakken S, Curran C, Cimino JJ: Perceived Information Needs and Communication Difficulties of Inpatient Physicians and Nurses. J Am Med Inform Assoc 2002, 9:564-69. 
29. Afifi WA, Weiner JL: Toward a theory of motivated information management. Communication Theory 2004, 14:167-190

30. Johnson KB, Gadd C: Playing smallball: Approaches to evaluating pilot health information exchange systems. Journal of Biomedical Informatics 2007, 40:S21-S26.

31. Forsythe DE, Buchanan BG, Osheroff JA, Miller RA: Expanding the concept of medical information: An observational study of physicians' information needs. Computers and Biomedical Research 1992, 25:181-200.

32. Clinical Classifications Software (CCS) for ICD-9-CM. [http://www.hcup-us. ahrq.gov/toolssoftware/ccs/ccs.jsp].

33. Lucas RH, Sanford SM: An Analysis of Frequent Users of Emergency Care at an Urban University Hospital. Annals of Emergency Medicine 1998, 32:563-568.

34. Hunt KA, Weber EJ, Showstack JA, Colby DC, Callaham ML: Characteristics of frequent users of emergency departments. Ann Emerg Med 2006, 48:1-8.

35. Locker TE, Baston S, Mason SM, Nicholl J: Defining frequent use of an urban emergency department. Emerg Med J 2007, 24:398-401.

36. Chronic Condition Indicator. [http://www.hcup-us.ahrq.gov/toolssoftware/ chronic/chronic.jsp].

37. Rabe-Hesketh S, Skrondal A: Multilevel and Longitudinal Modeling Using Stata. 2 edition. College Station, Tx: Stata Press; 2008.

38. Agresti A: Categorical Data Analysis Hoboken, NJ: John Wiley \& Sons; 2002.

39. Fitzmaurice G, Laird N, Ware J: Applied Longitudinal Analysis New York: John Wiley and Sons; 2004.

40. Heagerty P, Zeger S: Marginalized multilevel modles and likelihood. Statistical Science 2000, 15:29-46.

41. Vest JR, Zhao H, Jasperson J, Gamm LD, Ohsfeldt RL: Factors motivating and affecting health information exchange usage. Journal of the American Medical Informatics Association 2011, 18:143-149.

42. Vest JR, Gamm L, Ohsfeldt R, Zhao H, Jasperson J: Factors Associated with Health Information Exchange System Usage in a Safety-Net Ambulatory Care Clinic Setting. Journal of Medical Systems 2011, 1-7.

43. Bÿstrom $\mathrm{K}$, Järvelin $\mathrm{K}$ : Task complexity affects information seeking and use. Information Processing \& Management 1995, 31:191-213.

44. Kleinke JD: Dot-Gov: Market Failure And The Creation Of A National Health Information Technology System. Health Aff 2005, 24:1246-1262.

45. Johnson KB, Unertl KM, Chen Q, Lorenzi NM, Nian H, Bailey J, Frisse M: Health information exchange usage in emergency departments and clinics: the who, what, and why. Journal of the American Medical Informatics Association 2011, 18:690-697.

46. Shapiro JS, Kannry J, Kushniruk AW, Kuperman G, The New York Clinical Information Exchange Clinical Advisory S: Emergency Physicians' Perceptions of Health Information Exchange. J Am Med Inform Assoc 2007, 14:700-705.

47. Kellogg ND, the Committee on Child Abuse Neglect: Evaluation of Suspected Child Physical Abuse. Pediatrics 2007, 119:1232-1241.

48. Gorman PN, Helfand M: Information Seeking in Primary Care: How Physicians Choose Which Clinical Questions to Pursue and Which to Leave Unanswered. Med Decis Making 1995, 15:113-119.

49. Ely JW, Osheroff JA, Ebell MH, Chambliss ML, Vinson DC, Stevermer JJ, Pifer EA: Obstacles to answering doctors' questions about patient care with evidence: qualitative study. BMJ 2002, 324:710.

50. Classen DC, Kanhouwa M, Will D, Casper J, Lewin J, Walker J: The patient safety institute demonstration project: a model for implementing a local health information infrastructure. J Healthc Inf Manag 2005, 19:75-86.

51. Hripcsak G, Sengupta S, Wilcox A, Green RA: Emergency department access to a longitudinal medical record. J Am Med Inform Assoc 2007, 14:235-238.

52. Vest J, Jasperson J: How are health professionals using health information exchange systems? Measuring usage for evaluation and system improvement. Journal of Medical Systems.

53. Halamka J, Fournier GA: MA-SHARE MedsInfo-ED medication history pilot. Am J Med Qual 2006, 21:296-298.

54. Vest JR, Jasperson J: What should we measure? Conceptualizing usage in health information exchange. Journal of the American Medical Informatics Association 2010, 17:302-307.

Pre-publication history

The pre-publication history for this paper can be accessed here:

http://www.biomedcentral.com/1472-6947/11/78/prepub doi:10.1186/1472-6947-11-78

Cite this article as: Vest et al:: Use of a health information exchange system in the emergency care of children. BMC Medical Informatics and Decision Making 2011 11:78.

\section{Submit your next manuscript to BioMed Central and take full advantage of:}

- Convenient online submission

- Thorough peer review

- No space constraints or color figure charges

- Immediate publication on acceptance

- Inclusion in PubMed, CAS, Scopus and Google Scholar

- Research which is freely available for redistribution 